Supplement of Atmos. Chem. Phys., 15, 5815-5826, 2015

http://www.atmos-chem-phys.net/15/5815/2015/

doi:10.5194/acp-15-5815-2015-supplement

(C) Author(s) 2015. CC Attribution 3.0 License.

(c) (i)

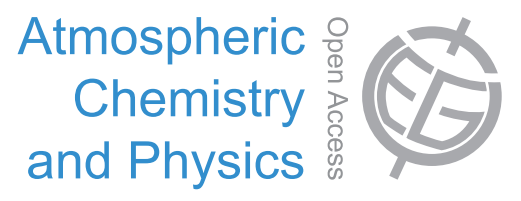

Supplement of

\title{
Quantifying contributions to the recent temperature variability in the tropical tropopause layer
}

W. Wang et al.

Correspondence to: W. Wang (wuke.wang @fu-berlin.de)

The copyright of individual parts of the supplement might differ from the CC-BY 3.0 licence. 
T GPS-RO (20 S-N) 16-21 km

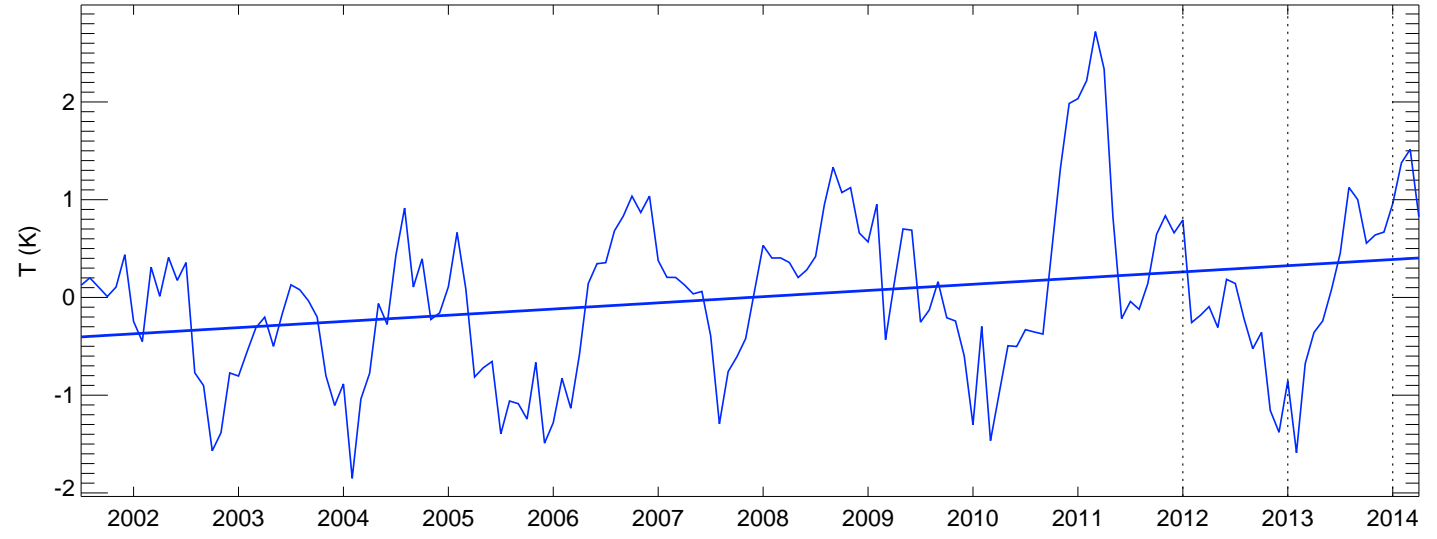

Figure S1: Deseasonalized time series of temperature anomalies from observations (GPSRO data), averaged between $20^{\circ} \mathrm{S}$ and $20^{\circ} \mathrm{N}$ latitude and between 16 and 21 $\mathrm{km}$ height. This figure shows large interannual temperature fluctuations. From this time series alone, the future development of temperatures in the TTL is not clear (see also Fig. S3 for a longer time series. Vertical lines indicate different end dates for the trend estimates in Fig. S2. 


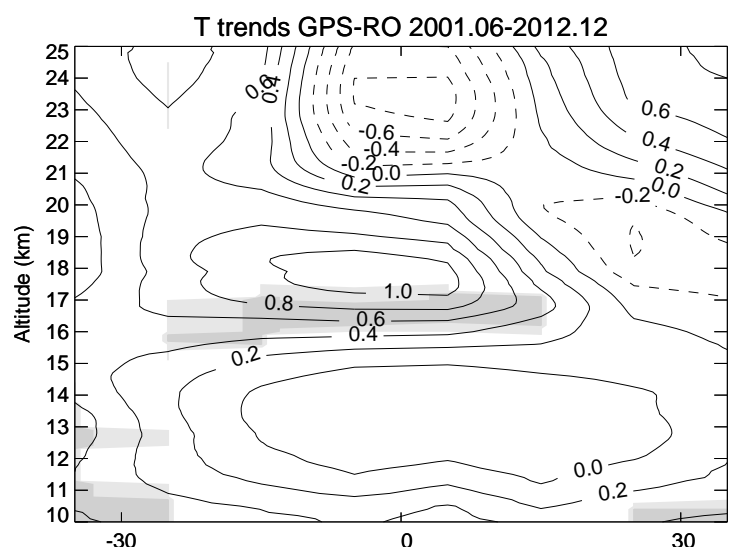

(a)

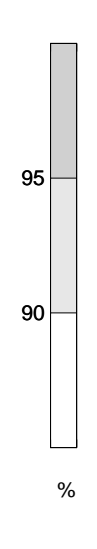

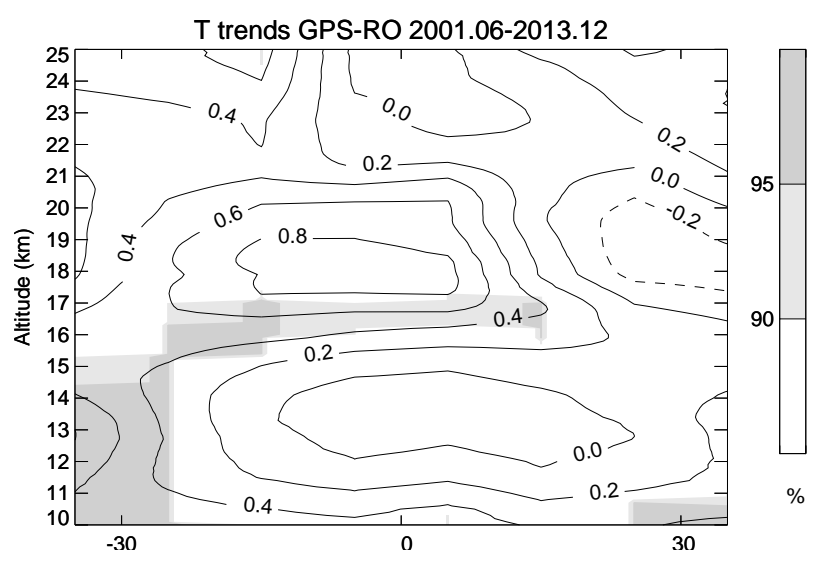

(b)

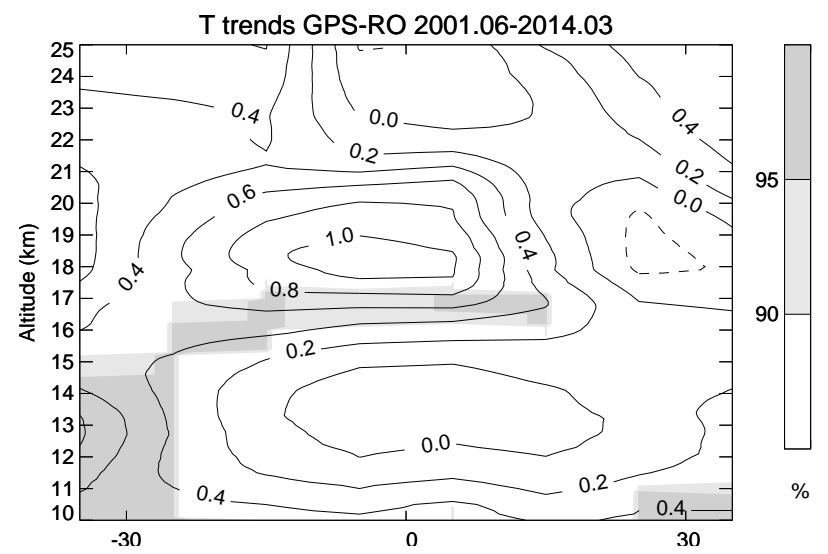

(c)

Figure S2: Same as in Fig. 2, but with different ending dates: (a) 31 December 2012; (b) 31 December 2013 and (c) 31 March 2014 (most recent data available). The trend calculations are sensitive to the ending date of the time series. 


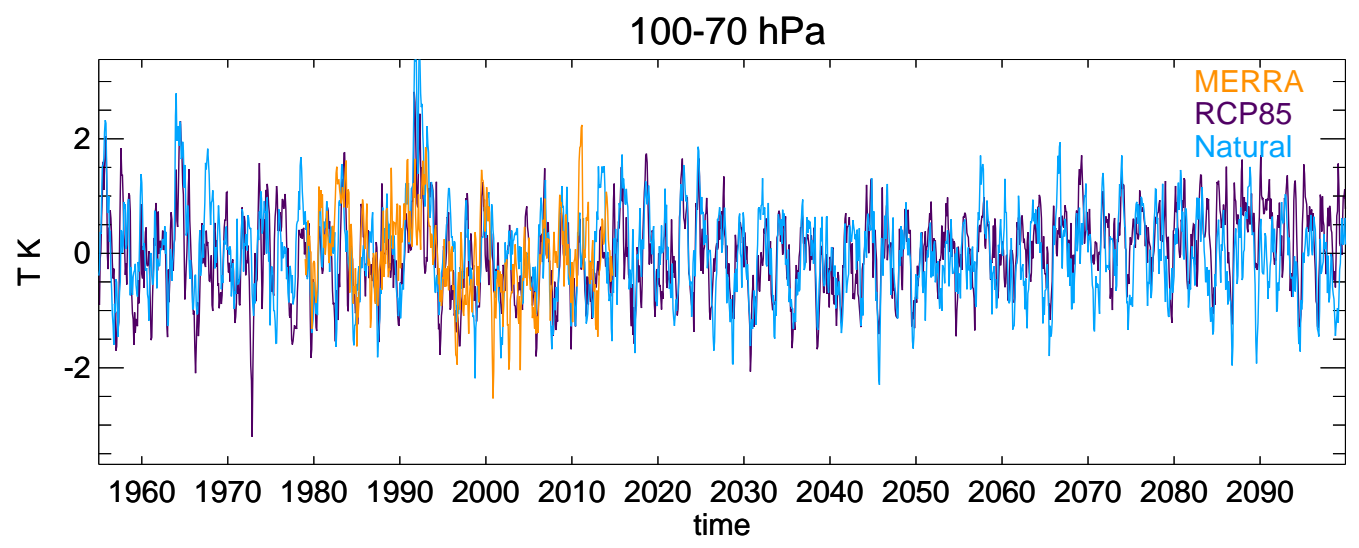

Figure S3: Deseasonalized time series of temperature anomalies from the Natural and RCP85 runs as well as the MERRA reanalysis data, averaged between $20^{\circ} \mathrm{S}$ and $20^{\circ} \mathrm{N}$ in latitude and between 100 and $70 \mathrm{hPa}$. Also over a longer time period than shown in Fig. S1, the TTL temperatures show large interannual variability from both model simulations and reanalysis data. The long-term temperature time series from the model simulations show a clear decadal to multidecadel signal. 